\title{
Feeding activity and swimming patterns of Acartia grani and Oithona davisae nauplii in the presence of motile and non-motile prey
}

\author{
Casper Ingerslev Henriksen ${ }^{1,2}{ }^{,}$Enric Saiz ${ }^{2, *}$, Albert Calbet ${ }^{2}$, \\ Benni Winding Hansen ${ }^{1}$ \\ ${ }^{1}$ Roskilde University, Department of Life Sciences and Chemistry, 4000 Roskilde, Denmark \\ ${ }^{2}$ Institut de Ciències del Mar, CSIC, P. Marítim de la Barceloneta 37-49, 08003 Barcelona, Catalunya, Spain
}

\begin{abstract}
The feeding behaviour of the nauplii of the copepods Acartia grani (calanoid) and Oithona davisae (cyclopoid) was investigated in relation to the different motility capabilities of their prey. The prey were the motile dinoflagellate Heterocapsa sp. (equivalent spherical diameter, ESD = $12.8 \mu \mathrm{m})$ and the non-motile diatom Thalassiosira weissflogii $(\mathrm{ESD}=14.4 \mu \mathrm{m})$. Functional response feeding experiments showed that $A$. grani nauplii exhibited higher ingestion rates on the motile than on the non-motile prey, with maximum daily rations of, respectively, 299 and $185 \%$ body $\mathrm{C} \mathrm{d}^{-1}$. O. davisae nauplii showed lower ingestion rates $\left(121 \%\right.$ body $\left.\mathrm{C} \mathrm{d}^{-1}\right)$ and were unable to feed on the non-motile prey. Video observations showed that $A$. grani nauplii moved with a continuous hopping behaviour, either in a straight or helical pattern; feeding events were observed mainly while swimming in helicoids. O. davisae nauplii exhibited a jump and sink behaviour, typical of ambush feeding. Both species showed changes in their behaviour when presented with the motile prey Heterocapsa $\mathrm{sp}$. This indicates that the nauplii are capable of adjusting their feeding behaviour to the different prey characteristics, thereby optimising ingestion rates.
\end{abstract}

KEY WORDS: Oithona davisae $\cdot$ Acartia grani $\cdot$ Nauplii $\cdot$ Feeding rates $\cdot$ Prey motility $\cdot$ Swimming patterns

Resale or republication not permitted without written consent of the publisher

\section{INTRODUCTION}

Encounters between organisms in the ocean are fundamental for predator-prey interactions. For the copepod-prey interaction, amongst others, the encounter depends on the relative swimming velocity of the predator and the prey (Gerritsen \& Strickler 1977). In this sense, some copepods have the capability to create feeding currents, increasing the water flow towards the copepod and, therefore, the encounter rate with prey (Strickler 1985, Van Duren et al. 2003). Encounter rate depends also on the distance at which a prey can be detected. This reaction distance will depend, additionally, on the threshold value of mechano- and chemoreceptors to trigger the copepod response and the strength of the prey signal (Paffenhöfer \& Lewis 1990, Svensen \& Kiørboe 2000). Finally, moderate small-scale turbulence augments prey encounter rate in ambush-feeding copepods (Kiørboe \& Saiz 1995, Saiz \& Kiørboe 1995, Saiz et al. 2003).

Calanoids and cyclopoids are the most important copepod orders in the plankton, and numerous studies have been conducted on the feeding and/or behaviour of the adults of these 2 groups (Uchima \& Hirano 1988, Paffenhöfer \& Lewis 1990, Tiselius et al. 1997, Svensen \& Kiørboe 2000, Paffenhöfer \& Mazzocchi 2002, Saiz et al. 2003, Seuront et al. 2004). Only recently some research has been conducted on the feeding behaviour of their first larval stages (nauplii) (Van Duren \& Videler 1995, Paffenhöfer et al. 1996, Titelman 2001, 
Titelman \& Kiørboe 2003a,b, Jiang \& Paffenhöfer 2004). This lack of knowledge contrasts with the fact that copepod nauplii are considered the most abundant multicellular zooplankters in the marine environment (Fryer 1986), and an important food source for many fish larvae (Dalpadado et al. 2000, Gaard \& Reinert 2002). To be able to better understand the predator-prey interactions in copepod nauplii, quantitative studies on their behaviour and feeding activity are fundamental.

Among the prey characteristics that influence copepod feeding, prey motility has a special relevance because, as mentioned above, it can affect encounter rates by either increasing the relative speed between prey and predator (Gerritsen \& Strickler 1977) or by facilitating detection of the prey by the predator because of the hydromechanical signal generated. The effect of prey motility on copepod feeding activity likely will depend on the behavioural characteristics of the copepod species as well. Many cyclopoid nauplii remain virtually motionless in the water while slowly sinking, relocating only occasionally with fast jumps. This has been referred as jump-sink behaviour (Titelman \& Kiørboe 2003a, Jiang \& Paffenhöfer 2004), and seems to correspond to an ambush strategy. In contrast, nauplii of calanoids seem to exhibit a more diversified behaviour, ranging from nearly $100 \%$ cruise moving mode to a more hop-like mode (Van Duren \& Videler 1995, Paffenhöfer et al. 1996, Titelman \& Kiørboe 2003a, Jiang \& Paffenhöfer 2004). From the point of view of prey encounter, the jump-sink behaviour mentioned above suggests a lower encounter, and thus lower feeding, rate in the presence of a non-motile prey than what is expected for a continuous-moving copepod. Therefore, we expect ambush-feeding predators like cyclopoids to be more affected by prey motility, increasing their feeding rate when confronted with a motile prey. In comparison, continuously moving or hopping calanoid nauplii would be expected to exhibit higher encounter and feeding rates due to their increased motility.

This study aims to provide new insights into the feeding behaviour of copepod nauplii by testing the effects of prey motility on encounter and feeding rates of copepods. To do that, we have exposed the nauplii of the copepods Acartia grani (Calanoida) and Oithona davisae (Cyclopoida) in laboratory incubations to 2 similarly sized, different prey: the non-motile diatom Thalassiosira weissflogii and the motile dinoflagellate Heterocapsa sp., and the nauplii feeding responses, motion patterns and reaction distances to prey have been determined.

\section{MATERIALS AND METHODS}

Acartia grani and Oithona davisae specimens came from continuous cultures at the Institut de Ciències del Mar located in Barcelona, Spain. They were kept separated in $20 \mathrm{l}$ transparent plastic tanks, at $20^{\circ} \mathrm{C}$ and with a $12 \mathrm{~h}$ day:12 h night cycle. A. grani was fed the Cryptophyceae Rhodomonas baltica (equivalent spherical diameter, ESD $=6.6 \mu \mathrm{m}$ ), and $O$. davisae was maintained with the heterotrophic dinoflagellate Oxyrrhis marina (ESD $=16.9 \mu \mathrm{m})$. To allow comparison between species, special care was taken to use similarsized nauplii. Due to length differences between newly hatched nauplii of $A$. grani and $O$. davisae different nauplii stages were used for each species (Stages NII and III for $A$. grani and Stages NIII and IV for $O$. davisae).

Typical carbon and nitrogen contents of the nauplii and algal species were determined with a NA2100 Carbon-Nitrogen Analyser (Table 1). Three replicate samples were taken for both nauplii and algae, as well as 3 blank samples. For the nauplii samples, a minimum of 4700 individuals was filtered per replicate. Size-carbon and size-nitrogen conversion factors for both predator and prey were determined and used to calculate weight-specific rates.

Nauplii feeding experiments. For the feeding experiments with Acartia grani, nauplii cohorts were obtained by removing adults from the culture with a $250 \mu \mathrm{m}$ mesh size sieve, and placing them in a new tank. These animals were kept with a concentration of Rhodomonas baltica at $8 \mathrm{ppm}$, and allowed to produce eggs for 15 to $20 \mathrm{~h}$. Thereafter, the eggs were collected and transferred to a new tank to hatch, where the recently hatched nauplii were grown at a $3 \mathrm{ppm} R$. baltica concentration. After $48 \mathrm{~h}$ the hatched nauplii had reached Stages NII to NIII and were ready to use for experiments.

Nauplii cohorts for Oithona davisae were made similarly. First, egg-bearing females were collected with a $130 \mu \mathrm{m}$ sieve and transferred into a hatching tank, from which the adults were removed after 15 to $20 \mathrm{~h}$,

Table 1. Typical values of size (either body length [mean $\pm \mathrm{SE}$ ] for nauplii or equivalent spherical diameter for algae), $\mathrm{C}$ and $\mathrm{N}$ contents (ng ind. ${ }^{-1}$ ) and $\mathrm{C}: \mathrm{N}$ weight ratio for Acartia grani and Oithona davisae nauplii, and for the algae Thalassiosira weissflogii and Heterocapsa sp. These values have been used to convert body size into carbon and nitrogen contents in the experiments

\begin{tabular}{|lcccc|}
\hline & A. grani & O. davisae & T. weissflogii & Heterocapsa sp. \\
\hline Size $(\mu \mathrm{m})$ & $165.5 \pm 2.5$ & $120.0 \pm 1.5$ & 14.4 & 12.8 \\
C contents & 40.1 & 32.2 & $220.5 \times 10^{-3}$ & $188.5 \times 10^{-3}$ \\
N contents & 10.2 & 8.0 & $32.9 \times 10^{-3}$ & $33.8 \times 10^{-3}$ \\
C:N & 3.95 & 4.05 & 6.7 & 5.6 \\
\hline
\end{tabular}


leaving the newly hatched nauplii in the tank. They were kept for $72 \mathrm{~h}$ on a diet of Oxyrrhis marina at 3 ppm before initiating the experiments. By then they would have reached Stages NIII to NIV. For both Acartia grani and $O$. davisae food concentrations were kept at the desired level in the corresponding tanks by daily adjustments.

The algal species used as prey in the feeding and behavioural experiments were a non-motile species (Thalassiosira weissflogii, ESD $=14.4 \mu \mathrm{m}$; Culture Collection of Algae and Protozoa, UK) and a motile species (the dinoflagellate Heterocapsa sp., ESD = $12.8 \mu \mathrm{m}$ ). They were cultivated in sterile environments in $1 \mathrm{l}$ flat bottom glass flasks with added $f / 2$-medium in a $12 \mathrm{~h}$ day:12 h night cycle at $100 \mu \mathrm{mol}$ photon $\mathrm{m}^{-2} \mathrm{~s}^{-1}$. In the case of the diatom $T$. weissflogii, silicon was also added. At least $3 \mathrm{~d}$ before initiation of the experiments, the cultures of $T$. weissflogii were stirred with aeration to facilitate the spine throw off, which otherwise could interfere with the feeding behaviour (Gifford et al. 1981, and authors' pers. obs.).

Feeding experiments were conducted in $72 \mathrm{ml}$ transparent plastic cell culture bottles and covered a range of algal concentrations from 39 to 2500 cells ml ${ }^{-1}$ to allow the determination of functional responses. In the case of Acartia grani versus Heterocapsa sp. an additional second experiment was conducted with algal cell concentrations from 625 to 4000 cells $\mathrm{ml}^{-1}$. This was done because saturation was not totally achieved in the first experiment. The range of algal concentrations was obtained by successive dilution of stock cultures. The algal suspensions were adjusted by enumerating 4 diluted replicate samples by triplicate counting using a Coulter Multisizer particle counter. Typically, 2 initial, 3 control (only prey) and 3 experimental (prey + nauplii) bottles were filled with prey suspension in a 3step filling procedure to ensure homogeneity between replicates. Nutrients were added to all bottles ( $5 \mathrm{ml} \mathrm{f/2}$ $\mathrm{l}^{-1}$ ) to compensate for differentiated algal growth in the experimental bottles due to possible nutrient excretion by nauplii, and to ensure excess of nutrients in all the bottles. The bottles were sealed with a double layer of plastic foil, preventing bubbles from forming, and capped. The bottles were mounted on a planktonwheel $(0.2 \mathrm{rpm})$, and were incubated at $\sim 20^{\circ} \mathrm{C}$ (19.6 to $20.8^{\circ} \mathrm{C}$ ), with a $12 \mathrm{~h}$ day: $12 \mathrm{~h}$ night cycle for ca. $24 \mathrm{~h}$. Initial and final samples of the experimental suspension were preserved with acidic Lugol's solution $(1 \%$ final concentration), and were kept in the dark at $4^{\circ} \mathrm{C}$ for later microscopic analysis of prey abundance (between 200 and 300 cells counted per replicate).

Clearance and ingestion rates were determined according to Frost (1972). Cell counts were converted into carbon and nitrogen units using conversion factors derived from Table 1 and average cell size from the
Coulter Multisizer counts when preparing the suspensions. Carbon- and nitrogen-specific rates were calculated using the average nauplii size determined for each experiment. In the case of Acartia grani versus Heterocapsa sp., the 2 independent experiments conducted to complete the functional response employed nauplii originating from different cohorts, therefore showing slightly different stage compositions and sizes (average body mass: 31.5 and $33.9 \mathrm{ng} \mathrm{C}$ ind. ${ }^{-1}$, respectively). In order to put together the data from these 2 experiments, the respective weight-specific ingestion rates were obtained and the ingestion rates on a per capita basis (cells ind. ${ }^{-1} \mathrm{~d}^{-1}$ ) were computed for an average nauplii (32.7 ng $\mathrm{C}$ ind. ${ }^{-1}$ ).

Video filming of nauplii. Behavioural observations of the nauplii were conducted in 2 different ways. The first one consisted of capturing live 2D video films of the animals under the presence of prey at low magnification. This was done with a CCD video camera fitted with a $100 \mathrm{~mm}$ macrophoto-lens and connected to a time-date recorder, a VCR and a monitor, thus providing live images at 50 fields $\mathrm{s}^{-1}$. A 21 transparent plastic cubic aquarium (13.5 cm side), filled with distilled water, was placed in front of the macro-lens. Then, a $72 \mathrm{ml}$ culture tissue plastic bottle, containing the nauplii and the algal suspension to be observed, was submerged inside the aquarium. It was given a minimum of $1 \mathrm{~h}$ to acclimatise before filming was initiated. Concentrations of algal cells and nauplii in the recordings were, respectively, 500 cells $\mathrm{ml}^{-1}$ and 2.7 nauplii $\mathrm{ml}^{-1}$. For each nauplii recording, a millimetre scale was attached to the tissue plastic bottle and filmed as well.

In order to better record the details of behavioural events and to be able to register feeding attacks, another set of observations was conducted at higher magnification. The set-up was similar to the first one, however, a horizontally placed dissecting microscope was used instead of the macro-lens (see Saiz \& Alcaraz 1991) and images were obtained at $25 \times$ magnification. Alga and nauplius concentrations were in the range of 3000 to 4000 cells $\mathrm{ml}^{-1}$ and 20 to 25 nauplii $\mathrm{ml}^{-1}$.

For both set-ups, filming was done in a temperature-controlled dark room $\left(19.8\right.$ to $\left.21.9^{\circ} \mathrm{C}\right)$ and the illumination consisted of backlighting from an infrared light source. Video observations were initiated at 20:00 h, which corresponded to the initiation of the laboratory night cycle, and lasted $\sim 60 \mathrm{~min}$ for the swimming observation and $\sim 120 \mathrm{~min}$ for the close-up filming.

Video analysis was carried out manually with a Panasonic HS1000-Edit station VCR. The full recording was played, and 20 nauplii that were in focus and provided a minimum of 20 displacements on the screen were randomly chosen for analysis. In the close-up filming, due to a lower presence of animals in focus 
and the few observed feeding attacks, the number of events was lower ( $\mathrm{n}=8$ to 11$)$. Nauplius trajectories were traced on a transparent acetate sheet placed on top of the monitor screen; afterwards they were digitalised on a flatbed scanner, and the trajectory coordinates were obtained with the software QuickTrace PPC for Macintosh after calibration. The coordinate data were transferred to Microsoft Excel, where the distance travelled, velocities and time budgets were computed.

Nauplii behaviour definitions. Three main different swimming behaviours were identified. For both Acartia grani and Oithona davisae nauplii, sinking was defined as a downward movement due to gravity solely. Jumping was an active movement defined as a rapid displacement of the animal. Quiet was defined as a lack of motion, normally after a jump, where the animal was positioned at the same place for a short period. It could have happened that the animal was actually very slowly sinking, but this was not detected because of the short time range and visual limitations.

Video analysis of nauplii feeding attacks. The distance between the nauplius and the prey was measured when an attack was effected, in which case the attack time, the handling time and the pre-attack behaviour was noted. Attack time was defined as the time from the initiation of the attack until the algal cell had disappeared. In most of the cases this was not easy to observe because of shadow from the nauplius itself; hence, only 5 to 7 complete successful attacks were observed in each food scenario. In addition, some attacks leading to eventual rejection of the prey item were recorded. Unless stated otherwise, values are arithmetic means and standard errors (SE).

To evaluate the error in the attack distance estimates based on 2-dimensional pictures, the depth of field of the observations was measured. This was done with a $10 \mu \mathrm{m}$ interval object micrometer mounted at an angle of $45^{\circ}$ to the lens axis. Focus on the object micrometer was set on the first line of the scale, and the following scale line not in focus indicated the maximum distance $(300 \mu \mathrm{m})$ at which a certain point source would be in focus. The maximum depth of field was calculated using the theorem of Pythagoras. The depth of field was $212 \mu \mathrm{m}$, and, in practical terms, this means that the error on the calculated distance values would be $\pm 106 \mu \mathrm{m}$.

\section{RESULTS}

\section{Feeding experiments}

Acartia grani nauplii ingestion rates followed a Holling Type II (on a per cell basis) functional response model on both prey (Fig. 1A, B). Maximum ingestion rates in terms of cells and carbon were, respectively, 50 and $62 \%$ higher when feeding on the motile prey (Table 2). The maximum intake of $A$. grani nauplii on the motile prey almost doubled that for the non-motile prey when expressed in terms of nitrogen (Table 2).

Oithona davisae nauplii only exhibited feeding on Heterocapsa sp. (Fig. 1C). Several experiments with different nauplii and algal concentrations were conducted to achieve a feeding response for $O$. davisae nauplii on the non-motile prey, always rendering no significant values. Regarding the feeding on Heterocapsa sp., O. davisae nauplii showed a similar-type response to Acartia grani, but overall with much lower maximum ingestion rates (Fig. $1 \mathrm{C}$, Table 2).

For both naupliar species clearance rates decreased with food concentration (Fig. 2), down to values of ca. 0.05 to $0.1 \mathrm{ml} \mathrm{ind}^{-1} \mathrm{~d}^{-1}$ at the highest food concentrations. At low food availability, high variability on clearance rates was observed (which rendered low $\mathrm{r}^{2}$ fitted models, Fig. 2). Maximum clearance rates $\left(F_{\max }\right.$, i.e. clearance rates before any saturating effects became meaningful) were estimated from the Holling Type II fit for ingestion rates (on a per cell basis) as the quotient $I_{\max } / K_{\mathrm{m}}$, where $K_{\mathrm{m}}$ is the half saturation constant for the Holling fit and $I_{\max }$ is the maximum ingestion rate. $F_{\max }$ for Oithona davisae nauplii was $40 \%$ lower than for Acartia grani nauplii (Table 2).

\section{Prey and predator motility}

The mean velocity of Heterocapsa sp. was obtained by randomly selecting 27 different cells and following each of them for a minimum of $2 \mathrm{~s}$. The results gave a mean $( \pm \mathrm{SE})$ transportation velocity of $0.087 \pm 0.004 \mathrm{~mm} \mathrm{~s}^{-1}$.

The Acartia grani nauplii exhibited a hop-like motion, with frequent and rapid small jumps (1.4 \pm $0.05 \mathrm{bl}$, body lengths) interrupted by very short periods, when the nauplii were quiet or slowly sinking (Table 3). Overall, the hop-like motility was characterised by either movement in a straight line or in a spiral-like pattern (helical movement, Fig. 3), either downward or upward, in which the nauplii always moved in short hops. It is important to note that cruise swimming, understood as a continuous movement of the animal without stops, was not observed in any case with $A$. grani nauplii. The hop-like behaviour was consistent whether the nauplii were moving in a straight line or in a helical pattern. A Wilcoxon 2-sample test on the percentage time of the total time allocated to the 3 different behaviours (jump, sink and quiet) proved that their time budgets were independent of prey motility ( $\mathrm{p}>0.24$ in all cases).

There were no significant differences between the lengths of the jumps when feeding on the 2 prey types 


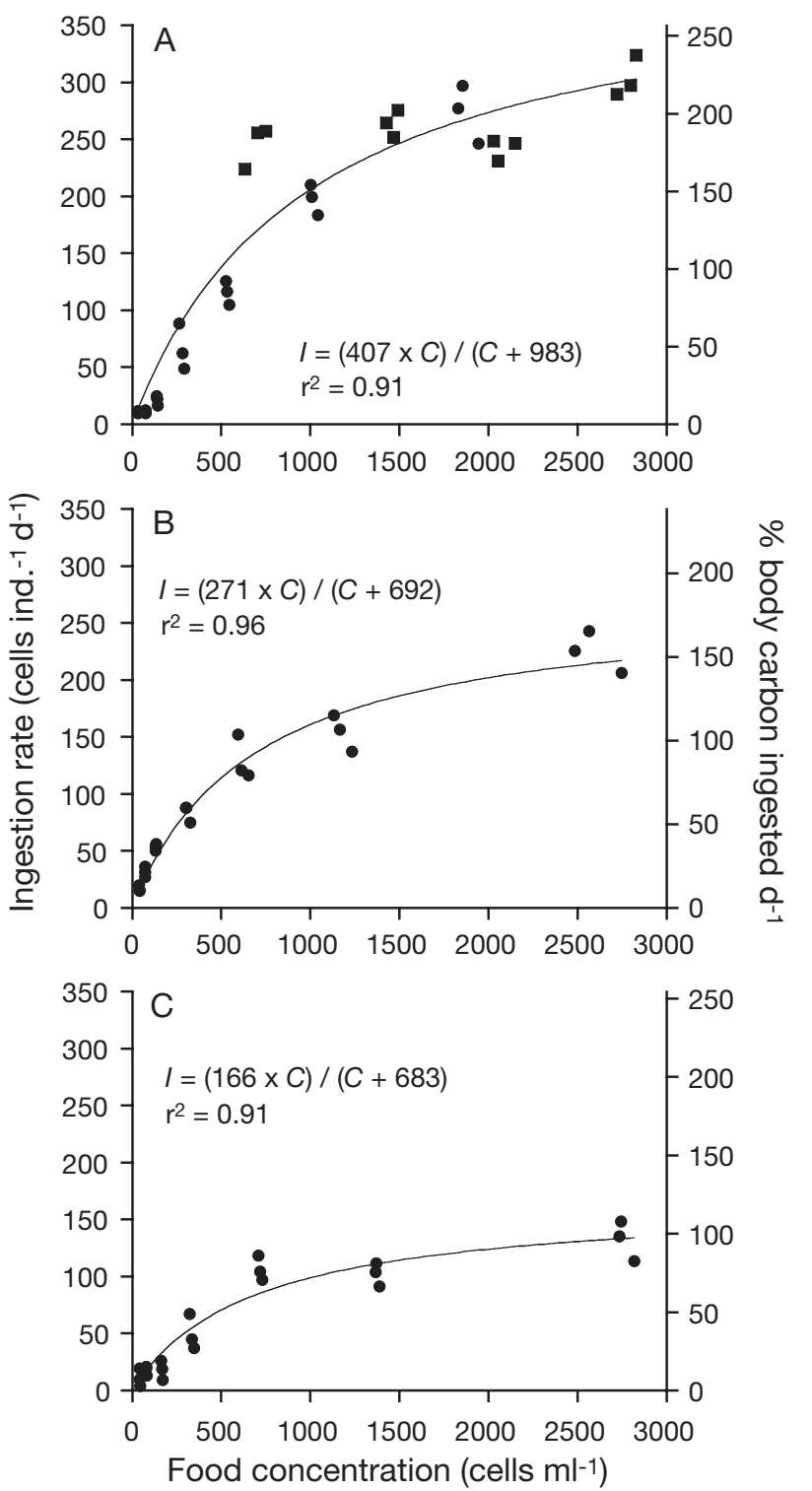

Fig. 1. Acartia grani and Oithona davisae. Ingestion rates (I) expressed as either cells ingested ind. ${ }^{-1} \mathrm{~d}^{-1}$ or percent body carbon ingested daily, as a function of the average food concentration $(C)$. Holling Type II equation is fitted to ingestion rates on a cell basis. (A) A. grani feeding on Heterocapsa sp. (squares: data from a second experiment also used for curve fitting, see 'Materials and methods'). (B) A. grani feeding on Thalassiosira weissflogii. (C) O. davisae feeding on Heterocapsa sp. Note that no significant ingestion rates were detected for $O$. davisae feeding on $T$. weissflogii; hence, no graph is presented

(Table 3, Wilcoxon test, $p>0.68$ ). The amount of time spent in helical motion was higher under the presence of non-motile prey $(45 \pm 0.1$ and $34 \pm 0.09 \%$ for nonmotile and motile prey, respectively), although the difference was not statistically significant (Table $3, p>$ 0.93). The rest of the time, the nauplii were jumping in a non-helical manner. It should be mentioned that due

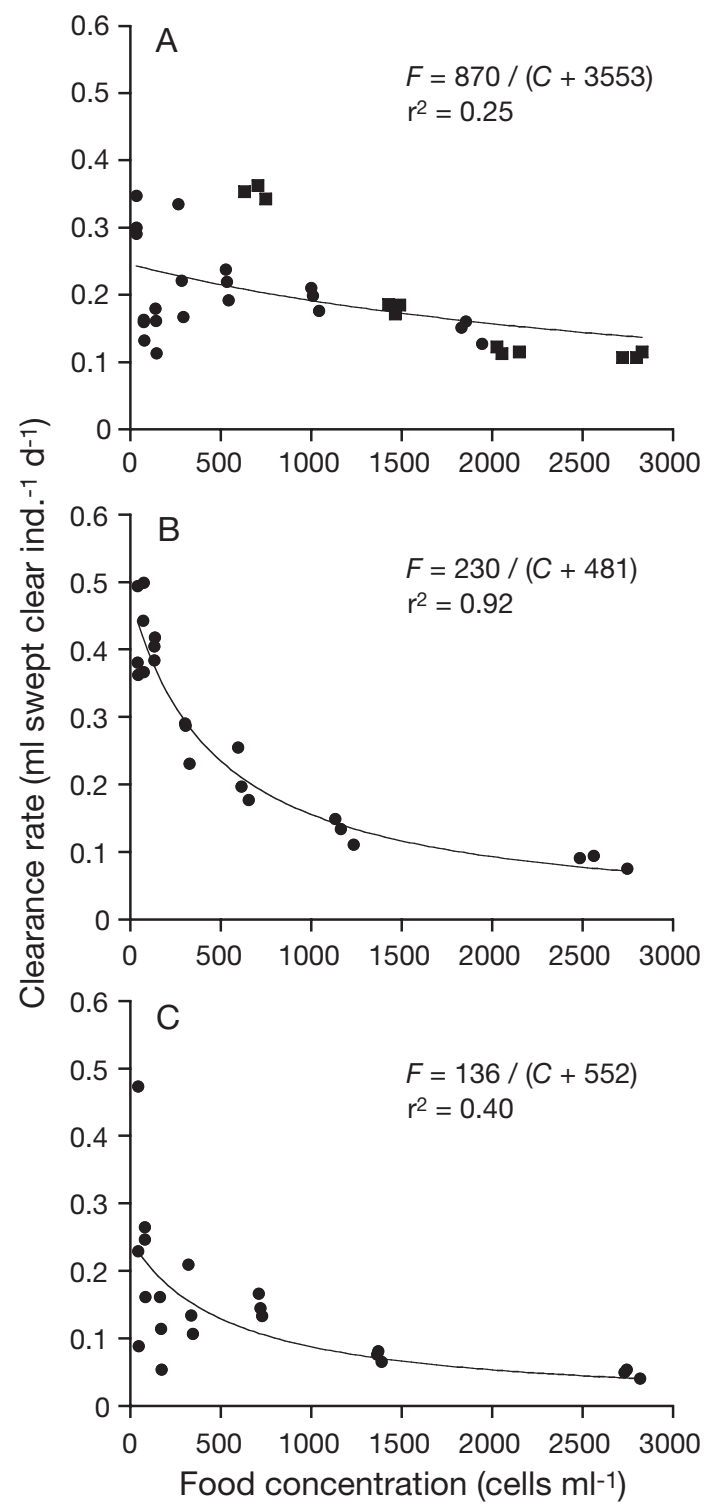

Fig. 2. Acartia grani and Oithona davisae. Clearance rates $(F)$ as a function of the average food concentration $(C)$. Details as in Fig. 1

to the relatively short observation time for each individual (2.1 to $14.7 \mathrm{~s}$ ), nauplii either performed one behaviour or the other, but only in a few cases were both motility behaviours observed in the same individual. Helical movement was performed at a faster speed in the presence of motile prey $(1.30 \pm 0.18$ and $0.69 \pm$ $0.10 \mathrm{~mm} \mathrm{~s}^{-1}$, respectively, for motile and non-motile prey; Wilcoxon, $\mathrm{p}>0.02$ ). This could be a consequence of the higher jump frequency $\left(226 \pm 23\right.$ jumps $\left.\mathrm{min}^{-1}\right)$ in the presence of the motile prey compared to the nonmotile prey $\left(196 \pm 14\right.$ jumps $\left.\min ^{-1}\right)$. On 2 occasions, both with a non-motile diet, the nauplii remained in the same position while spinning frenetically around themselves. This type of behaviour is not presented in 
Table 2. Acartia grani and Oithona davisae. Maximum ingestion and clearance rates of nauplii feeding on Heterocapsa sp. (Het.) and Thalassiosira weissflogii (T.w.). Data obtained from the Holling Type II equations of Fig. 1. Body mass of nauplii is also given

\begin{tabular}{|c|c|c|c|c|c|}
\hline Scenario & $\begin{array}{l}\text { Body mass } \\
\text { (ng C ind.- } .^{-1}\end{array}$ & $\begin{array}{r}\text { Maxi } \\
\text { (cells ind } .^{-1} \mathrm{~d}^{-1} \text { ) }\end{array}$ & $\begin{array}{l}\text { lum ingestion ra } \\
\left(\% \text { body } \mathrm{C} \mathrm{d}^{-1}\right)\end{array}$ & $\begin{array}{l}\text { te }\left(I_{\max }\right) \\
\quad\left(\% \text { body } \mathrm{N} \mathrm{d}^{-1}\right)\end{array}$ & $\begin{array}{l}\text { Maximum clearance rate }\left(F_{\max }\right) \\
\left(\mathrm{ml} \text { ind } .^{-1} \mathrm{~d}^{-1}\right)\end{array}$ \\
\hline A. grani vs. Het. & 32.7 & 407 & 299 & 212 & 0.41 \\
\hline A. grani vs. T.w. & 32.6 & 271 & 185 & 109 & 0.39 \\
\hline O. davisae vs. Het. & 33.3 & 166 & 121 & 88 & 0.24 \\
\hline
\end{tabular}

Table 3. Acartia grani and Oithona davisae. Summary of behavioural variables (mean \pm SE) analysed to describe the behaviour of the nauplii when offered Heterocapsa sp. (Het.) and Thalassiosira weissflogii (T.w.). Values expressed as body lengths or body lengths per second are in parentheses. ${ }^{*}$ : not enough data to calculate SE

\begin{tabular}{|c|c|c|c|c|}
\hline & Acartia vs. Het. & Acartia vs. T.w. & Oithona vs. Het. & Oithona vs. T.w. \\
\hline Percentage of time sinking & $48.2 \pm 4.9$ & $43.4 \pm 4.2$ & $98.2 \pm 0.15$ & $98.9 \pm 0.1$ \\
\hline Percentage of time jumping & $13.3 \pm 1.5$ & $11.5 \pm 1.1$ & $1.60 \pm 0.15$ & $0.93 \pm 0.08$ \\
\hline Percentage of time quiet & $38.4 \pm 3.6$ & $44.0 \pm 3.6$ & $0.02^{*}$ & $0.08^{*}$ \\
\hline Sinking event duration (s) & $0.76 \pm 0.1$ & $0.86 \pm 0.09$ & $3.3 \pm 0.3$ & $5.1 \pm 0.3$ \\
\hline Jump frequency (jumps $\min ^{-1}$ ) & $226 \pm 23.0$ & $196 \pm 14.0$ & $24 \pm 2.0$ & $14 \pm 1.1$ \\
\hline Jump distance (mm) & $\begin{array}{c}0.18 \pm 0.006 \\
(1.4 \pm 0.05)\end{array}$ & $\begin{array}{c}0.18 \pm 0.008 \\
(1.4 \pm 0.06)\end{array}$ & $\begin{array}{c}0.41 \pm 0.02 \\
(3.6 \pm 0.2)\end{array}$ & $\begin{array}{c}0.43 \pm 0.03 \\
(3.8 \pm 0.3)\end{array}$ \\
\hline Sinking distance (mm) & $\begin{array}{c}0.063 \pm 0.007 \\
(0.49 \pm 0.05)\end{array}$ & $\begin{array}{c}0.070 \pm 0.007 \\
(0.55 \pm 0.06)\end{array}$ & $\begin{array}{c}0.24 \pm 0.02 \\
(2.1 \pm 0.2)\end{array}$ & $\begin{array}{c}0.26 \pm 0.02 \\
(2.3 \pm 0.2)\end{array}$ \\
\hline Jump velocity $\left(\mathrm{mm} \mathrm{s}^{-1}\right)$ & $\begin{array}{r}4.8 \pm 0.17 \\
(37.3 \pm 1.3)\end{array}$ & $\begin{array}{r}5.2 \pm 0.15 \\
(40.5 \pm 1.2)\end{array}$ & $\begin{array}{c}9.7 \pm 0.5 \\
(85.8 \pm 4.6)\end{array}$ & $\begin{array}{c}10.2 \pm 0.5 \\
(89.8 \pm 4.1)\end{array}$ \\
\hline Sinking velocity $\left(\mathrm{mm} \mathrm{s}^{-1}\right)$ & $\begin{array}{c}0.082 \pm 0.01 \\
(0.64 \pm 0.09)\end{array}$ & $\begin{array}{c}0.082 \pm 0.006 \\
(0.63 \pm 0.05)\end{array}$ & $\begin{array}{c}0.079 \pm 0.004 \\
(0.69 \pm 0.03)\end{array}$ & $\begin{array}{c}0.053 \pm 0.002 \\
(0.46 \pm 0.02)\end{array}$ \\
\hline
\end{tabular}

Table 4. Acartia grani and Oithona davisae. Behavioural variables (mean \pm SE) describing the feeding attacks of nauplii on Heterocapsa sp. (Het.) and Thalassiosira weissflogii ( $T . w$.$) . Values expressed as body lengths are in parentheses.$ Notice that $O$. davisae did not feed on $T$. weissflogii and consequently no data are presented. n: number of observations

\begin{tabular}{|lccc|}
\hline & A. grani vs. Het. & A. grani vs. T.w. & O. davisae vs. Het. \\
\hline Attack duration (s) & $0.06 \pm 0.007$ & $0.06 \pm 0.003$ & $0.08 \pm 0.01$ \\
& $\mathrm{n}=10$ & $\mathrm{n}=11$ & $\mathrm{n}=8$ \\
Handling duration $(\mathrm{s})$ & $0.33 \pm 0.04$ & $0.44 \pm 0.2$ & $0.51 \pm 0.08$ \\
& $\mathrm{n}=7$ & $\mathrm{n}=9$ & $\mathrm{n}=6$ \\
Attack distance $(\mu \mathrm{m})$ & $91 \pm 27$ & $96 \pm 18$ & $113 \pm 22$ \\
& $(0.73 \pm 0.21)$ & $(0.76 \pm 0.15)$ & $(1.0 \pm 0.19)$ \\
& $\mathrm{n}=10$ & $\mathrm{n}=10$ & $\mathrm{n}=6$ \\
Pre-attack behaviour & Helical $(\mathrm{n}=10)$ & Helical $(\mathrm{n}=9)$ & Sinking $(\mathrm{n}=8)$ \\
& & Straight $(\mathrm{n}=2)$ & \\
\hline
\end{tabular}

Table 3 due to its low frequency (2 observations) and percentage $(1.07 \%)$ of total time.

Oithona davisae nauplii exhibited swimming patterns different than those of Acartia grani nauplii when offered both prey. Their overall motility can be characterised by jump-sink behaviour dominated by long jumps of $3.7 \pm 0.18 \mathrm{bl}$, both upwards and downwards, followed by long sinking periods (Fig. 4). Each sinking sequence was followed by a jump and a new sinking period. $O$. davisae spent $\sim 98 \%$ of the total time sinking and $\sim 1 \%$ of the time jumping (Table 3). There was no significant difference in jump length between prey types (Wilcoxon, p > 0.9), although they dedicated considerably more time to jumping in the presence of the motile prey (Wilcoxon, p > 0.0008). When $O$. davisae nauplii were on a non-motile diet, they spent significantly more time in each sinking event $(5.1 \pm 0.3$ versus $3.3 \pm 0.3 \mathrm{~s}$; $\mathrm{p}<0.001)$. O. davisae nauplii jump frequency was significantly higher (Wilcoxon test, $\mathrm{p}<0.001$ ) when offered the motile prey $(24 \pm 2$ jumps $\left.\mathrm{min}^{-1}\right)$ compared to the non-motile diet $(14 \pm 1.1$ jumps $\min ^{-1}$ ).

\section{Feeding attacks by nauplii}

Nauplii of Acartia grani seemed to be searching for food only when involved in a helical movement pat- 


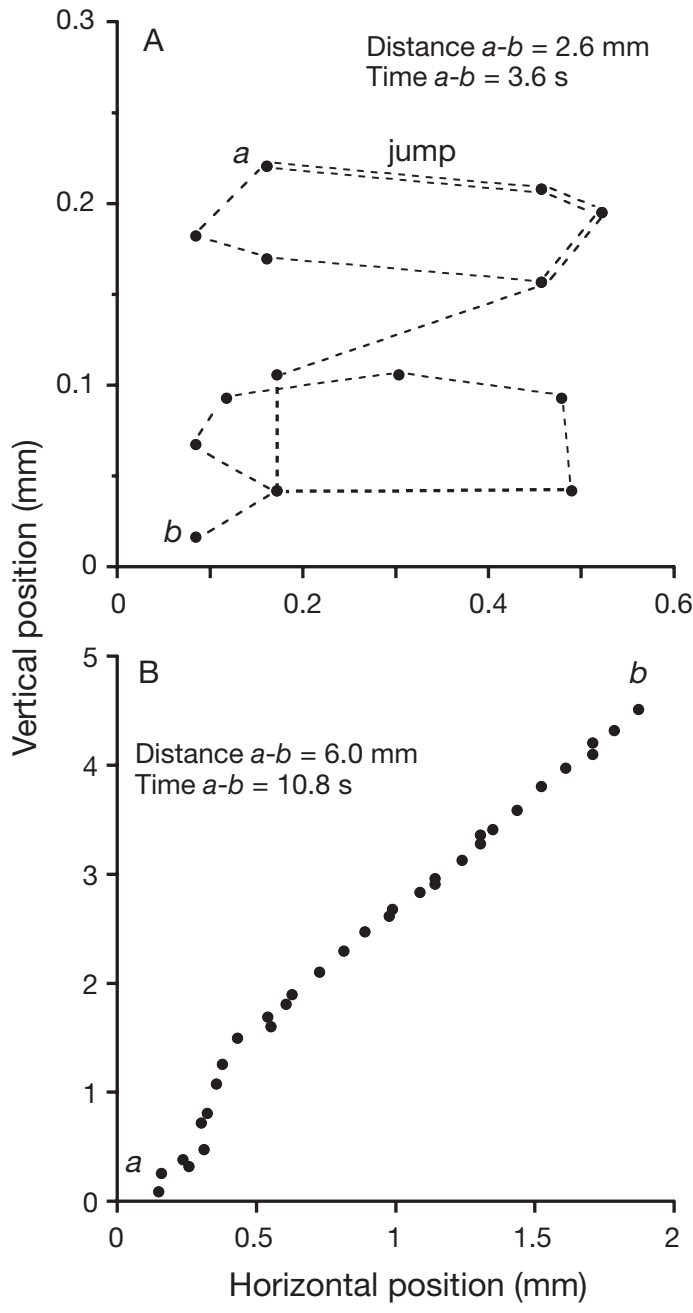

Fig. 3. Acartia grani. Representative examples of the 2 swimming behaviours observed in nauplii: (A) helical and (B) straight line motion. Note the different scales used in both panels and between axes

tern. This statement is based on the fact that in 19 out of 21 attack observations the nauplii were performing helical movement prior to the attack. Only in 2 cases were pre-attack nauplii moving in a straight line (Table 4). A rapid continuous movement of the appendages (likely to handle the prey) followed each successful attack, while the animal was moving in short pulses. For Oithona davisae, feeding-attack observations were only made with the motile prey, because of no registered feeding when offered the non-motile prey. $O$. davisae nauplii were always in periods of sinking prior to the observed attacks. Each attack was followed by a 'smooth gliding' behaviour, in which the animal gave the impression of handling and ingesting the algal cell.

For Acartia grani nauplii, attack duration was consistent regardless of prey type, and averaged $0.06 \mathrm{~s}$;
Oithona davisae nauplii, on the contrary, spent more time in each attack $(0.08 \mathrm{~s}$, Table 4$)$. This difference, however, was mostly a result of the longer attack distance completed by $O$. davisae nauplii. A. grani attack distances did not differ regardless of whether the animal was offered the motile or the non-motile prey (Table 4, Wilcoxon, $\mathrm{p}>0.35$ ). Handling duration was approximately $30 \%$ higher with Thalassiosira weissflogii than with Heterocapsa sp., although the differences were not significant $(p>0.75)$, likely due to the low number of attacks fully observed. In the case of $T$. weissflogii as prey, some cells were rejected (4 cases out of 11 attacks) and, thus, not ingested. It is worth mentioning that during the microscopic counting of $T$. weissflogii cells from the grazing bottles with $A$. grani nauplii, the algae showed signs of deterioration, which could be an indication of sloppy feeding. This qualitative observation, together with the high number of rejections observed for A. grani nauplii when feeding on $T$. weissflogii, gives high credibility to sloppy feeding in this particular feeding scenario.

\section{DISCUSSION}

The feeding rates reported here for nauplii of Acartia grani and Oithona davisae fall within the range of values found in the limited literature on the subject. For instance, field experimentation with Calanus nauplii rendered daily rations of up to $40 \%$ body $\mathrm{C} \mathrm{d}^{-1}$ (Irigoien et al. 2003). For smaller nauplii, such as Oncaea mediterranea, Paffenhöfer (1993) reported daily rations of $105 \%$ in laboratory experiments. Higher ingestion rates have been reported for Calanus pacificus (100 to 150\%; Fernández 1979), Calanus helgolandicus (110 to 297\%; Rey et al. 2001) and Rhin-

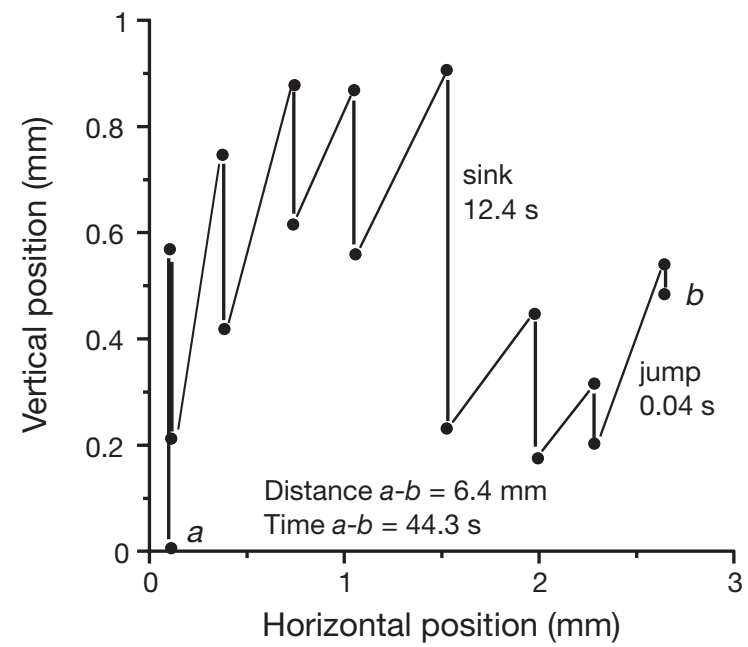

Fig. 4. Oithona davisae. Representative example of the jump and sink swimming behaviour observed in nauplii 
calanus nasutus (80 to $227 \%$; Mullin \& Brooks 1967). The maximum daily rations found in our study (299 and $121 \%$ body $\mathrm{C} \mathrm{d}^{-1}$ for $A$. grani and $O$. davisae nauplii, respectively) are within the higher range of the values found in the literature.

Regarding clearance rates, again it is difficult to find enough data with which to compare. The maximum clearance rates observed in our study varied between 0.2 and $0.4 \mathrm{ml}$ ind. ${ }^{-1} \mathrm{~d}^{-1}$, whereas the lowest rates, at high food concentrations, were around 0.05 to $0.1 \mathrm{ml}$ ind. ${ }^{-1} \mathrm{~d}^{-1}$. These values were somewhat higher than those in previous reports for small nauplii. For instance, Berggreen et al. (1988) reported clearance rates of ca. $0.044 \mathrm{ml}$ ind..$^{-1} \mathrm{~d}^{-1}$ for Acartia tonsa nauplii feeding on Thalassiosira weissflogii at a 0.65 ppm concentration. At a comparable concentration, similarly weighted Acartia grani would clear $0.25 \mathrm{ml}$ ind. ${ }^{-1} \mathrm{~d}^{-1}$.

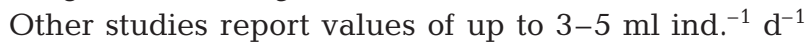
for much larger calanoid species nauplii (e.g. $0.4 \mu \mathrm{g} \mathrm{C}$ ind. $^{-1}$, Irigoien et al. 2003; 2.8 to $4.8 \mu \mathrm{g} \mathrm{C}$ ind. ${ }^{-1}$, Turner et al. 2001).

The nauplii species studied in this work showed conspicuously different swimming behaviours. Acartia grani nauplii swimming was characterised by jerky jumping (referred to as hopping behaviour), as displayed by many other calanoid nauplii species (Titelman \& Kiørboe 2003a). Such behaviour is characterised by a high frequency of jumping, e.g. 196 to 226 jumps $\min ^{-1}$ for $A$. grani nauplii (present study) and 90 to 183 jumps $\mathrm{min}^{-1}$ for Acartia tonsa nauplii (Titelman \& Kiørboe 2003a). Oithona davisae nauplii, however, typically displayed low-frequency jumpsink behaviour (14 to 24 jumps min $^{-1}$ ), which is a characteristic pattern associated with cyclopoids (Paffenhöfer \& Mazzocchi 2002). It is important to note here, however, that the jumps that characterise both behaviours are short (1.4 bl for A. grani nauplii, 3.6 to $3.8 \mathrm{bl}$ for $O$. davisae nauplii), far from the displacements reported for escape reactions.

Prior to our study, the effects prey motility could have on the consumption rates of nauplii were not known. Copepod nauplii have simplified feeding appendages, and, accordingly, if they generate any feeding currents at all these should be weak (Paffenhöfer 1998). Copepod nauplii, then, must rely mainly on a raptorial feeding mode, detecting and seizing prey individually. Raptorial feeding should not preclude, in principle, that copepod nauplii could consume motile and non-motile prey indiscriminately. The responses to prey motility exhibited by Acartia grani and Oithona davisae nauplii in this work were very different. A. grani nauplii cleared both prey at similar rates, independent of their motility. One would expect that the motility of Heterocapsa sp. would enhance the encounter rate with $A$. grani nauplii. Very likely
Heterocapsa sp. velocity was too small compared to A. grani nauplii speed to contribute to the predator-prey velocity difference driving encounter rate (Gerritsen \& Strickler 1977). An alternative explanation could be that any enhancement in encounter rate with Heterocapsa sp. might have been balanced if Heterocapsa sp. had the ability to escape naupliar attacks, resulting in no enhancement of feeding overall. However, this does not seem plausible, firstly, because during video observations no escape responses were registered in Heterocapsa sp., and, secondly, because Jakobsen (2001) did not find escape responses in dinoflagellates when exposed to a siphon flow. An interesting conclusion stemming from these results is that, even if A. grani nauplii detect prey by mechanoreception, chemoreception must work similarly well for them to detect the non-motile Thalassiosira weissflogii.

In terms of ingestion rate, there were meaningful differences in the maximum values observed as a function of prey. Maximum daily rations of Acartia grani nauplii on Heterocapsa sp. were 62 and $94 \%$ higher on a carbon and nitrogen basis, respectively, than those fed on Thalassiosira weissflogii. These differences in daily rations between the motile and non-motile prey are not necessarily related to food quality, because the $\mathrm{C}: \mathrm{N}$ ratio of both algal species was similar. Likely, the feeding saturation at a lower rate in the case of $T$. weissflogii (271 cells ind. ${ }^{-1} \mathrm{~d}^{-1}$ ) was due to the fact that these diatoms fill up the copepod gut volume faster than the naked Heterocapsa sp., because of their silicon frustules, allowing for a lower cell packaging in the copepod gut and, therefore, limiting the ingestion rate. In addition, the qualitative observations of broken T. weissflogii cells during sample counting and the observations of $T$. weissflogii rejections by A. grani nauplii suggest that palatability may play a major issue limiting the maximum ingestion rates. Another nonexclusive explanation might be that the longer handling time observed for A. grani nauplii when offered T. weissflogii compared to when offered Heterocapsa sp. (although not statistically significant) might result in less time allocated to food searching and, therefore, lead to lower effective encounter and clearance rates at high food concentrations.

Our observations on nauplii behaviour agree, in general, with the results from the incubation experiments mentioned above. Thus, the presence or absence of motility in the offered prey also had an effect on the swimming behaviour of the Acartia grani nauplii. In the presence of Heterocapsa sp., the nauplii of $A$. grani had almost double the transportation velocity when doing helical swimming than in the presence of the non-motile prey. Such changes in predator swimming velocity when in helical mode must result in a combined effect on encounter and 
feeding rates. This statement is supported by the fact that $90 \%$ of the observed A. grani nauplii feeding attacks occurred while in the helical swimming pattern. In fact, from these observations we hypothesise that helical movement would be an optimised search strategy for prey within a food patch, and, therefore, is directly associated with feeding (whereas straight line movement in A. grani nauplii could be interpreted as a search strategy for food-rich patches). The mechanisms underlying these changes in behaviour are not clear. Actually, the lower swimming velocity registered in $A$. grani nauplii in the presence of non-motile prey could just as well be interpreted as the result of a lower 'quality' value in Thalassiosira weissflogii, as suggested by the sloppy-feeding observations.

Regarding Oithona davisae nauplii, several attempts showed no feeding on the non-motile Thalassiosira weissflogii. Previous studies have indicated a low capability of adults and nauplii of Oithona spp. to feed on non-motile prey, both in the laboratory (Uchima \& Hirano 1986) and in natural conditions (Atkinson 1995), although diatoms have also been reported in their diet (Hopkins et al. 1993, Atkinson 1996, Atkinson et al. 1996, Atienza et al. 2006). The low capability of Oithona copepodites to feed on nonmotile prey has been attributed to the lack of feeding currents (Paffenhöffer 1993), which obliges the copepod to ambush feed. Ambush feeders rely on motile prey to be able to achieve a significant encounter rate with prey (Kiørboe \& Saiz 1995). According to our results this seems to be the case for the naupliar stages of $O$. davisae, since they attack their prey in an ambush mode. The fact that both motile and nonmotile prey had similar size excludes prey size as an alternative explanation for the dietary preference observed in O. davisae nauplii. Although previous work has suggested the role of chemical prey detection in the feeding of $O$. similis (González \& Smetacek 1994), Svensen \& Kiørboe (2000) showed that such a mechanism would not be an advantage in ambush-feeding copepods, like Oithona.

The maximum ingestion rates of Oithona davisae nauplii were substantially lower than those exhibited by Acartia grani nauplii. This lower intake seems to be a penalty for the ambush-feeding mode, which restricts prey encounter rates. Relying on prey motility to warrant prey encounters and feeding obviously sets a lower limit to the maximum daily ration a copepod can obtain in comparison with cruising or suspension feeders, which can scan a large volume of water for potential prey. The fewer encounters $O$. davisae nauplii exhibited in the presence of either motile or nonmotile prey, as compared to A. grani nauplii, would only be an ecological success if it meant metabolic sav- ings in other areas. Oithona is assumed to have lower metabolic demands than calanoids, providing an energetic advantage that allows it to thrive in environments at a low nutrient threshold (Paffenhöfer 1993, Castellani et al. 2005). This adaptation may be due to the lack of 2 energy-demanding characters: a feeding current and an active motility pattern. However, other adaptive morphological and sensorial traits, through evolutionary selection, may also help $O$. davisae nauplii to survive in such environments (Paffenhöfer 1998). $O$. davisae nauplii perceived approaching Heterocapsa sp. from further away than $A$. grani nauplii. The perceptive reaction distance is the single factor having the greatest effect on the encounter rate between a predator and its prey, because reaction distance scales squared with encounter rate (Kiørboe \& Saiz 1995).

The behavioural response of Oithona davisae nauplii to prey motility was different than that exhibited by Acartia grani. As mentioned above, O. davisae nauplii are ambush feeders and detect their prey while slowly sinking. The present results showed that $O$. davisae nauplii increased their average duration of sinking events by $55 \%$ in the presence of the non-motile prey as compared to the motile one (Table 3). Furthermore, their jump frequency was as low as 14 jumps min $^{-1}$ when presented with the non-motile prey and rose to 24 jumps $\mathrm{min}^{-1}$ in the presence of the motile prey (Table 3). As the motile and non-motile prey concentrations were the same, such changes in behaviour are likely triggered by the swimming capability of Heterocapsa sp. and by the ability of $O$. davisae nauplii to detect it, as evidenced by the feeding incubations.

It is interesting to note the behavioural changes in Oithona davisae nauplii in the presence of the nonmotile prey (longer sinking events, lower transportation velocity and lower jump frequency) agree well with the reported effects of filtered seawater (no food) on Acartia clausi adults (Takahashi \& Tiselius 2005). Such behavioural changes could indicate a strategy to save energy in an environment in which they are not able to sustain their normal energy demands through accessible food.

Finally, swimming behaviour has implications, not only for feeding, but also for the exposure to predation risks. Acartia grani nauplii showed a maximum of 226 jumps $\mathrm{min}^{-1}$ with the motile prey and 196 jumps $\mathrm{min}^{-1}$ when offered the non-motile prey (Table 3). Sinking nauplii are hydrodynamically almost undetectable, since the distance at which they can be detected by a predator tends towards zero (Titelman \& Kiørboe 2003b). Low-frequency jump-sink nauplii (e.g. Oithona davisae) generate a small hydrodynamic signal, whereas high-frequency jumpers (e.g. A. grani nauplii) would be at the highest risk (Titelman \& Kiørboe 2003b). By spending more time in a low-velocity type 
of behaviour, such as sinking, a prey, in this case $O$. davisae nauplii, may reduce the hydrodynamic signal that can be perceived by a predator, and thus limit the time exposed to predators (Titelman 2001).

\section{CONCLUSIONS}

Acartia grani and Oithona davisae nauplii clearly show different behaviours and feeding performances. The swimming of $A$. grani nauplii can be described as a typical high-frequency hopping behaviour. Feeding seems to be associated with helical paths, as a strategy to optimise water clearing. In contrast, $O$. davisae nauplii are typical ambush feeders, which exhibit lowfrequency jump-sink behaviour and should be less conspicuous to potential predators and prey. These different strategies, which commit $O$. davisae to feeding on motile prey, result, overall, in lower daily rations in comparison to those of $A$. grani nauplii. Prey motility can enhance encounter and feeding rates, but other factors like cell-packaging restrictions in the gut and lower palatability of prey can set the limits to actual feeding rates.

Finally, copepod nauplii showed plasticity in their behaviour as a function of the presence or absence of motility in potential prey. The fact that not only prey but predators are subject to behavioural changes has important implications for encounter- and individualbased models, which must take into account such variability to improve their predictive power.

Acknowledgements. This work was supported by the Spanish Ministry of Education and Science Grants ZOOTRANSFER (REN 2001-1693) and MICROROL (CTM-2004-02575/MAR) to E.S. and A.C., respectively, and by The Danish National Research Council (Grant No. 21-01-0549) to B.W.H. Financial support was furthermore provided by grants from the Danish foundations Knud Højgaards Fond, Nordea Danmark Fonden, Johannes Schmidts Legat for Havforskning, Eiler Kølpin Petersens Legat and Ludvigsens Legat. We are also very grateful to Dr. P. Tiselius for constructive comments on the manuscript.

\section{LITERATURE CITED}

Atienza A, Calbet A, Saiz E, Alcaraz M, Trepat I (2006) Trophic impact, metabolism, and biogeochemical role of the marine cladoceran Penilia avirostris and the codominant copepod Oithona nana in NW Mediterranean coastal waters. Mar Biol 150:221-235

Atkinson A (1995) Omnivory and feeding selectivity in five copepod species during spring in the Bellingshausen Sea, Antarctica. J Mar Sci 52:385-396

Atkinson A (1996) Subantarctic copepods in an oceanic, low chlorophyll environment: ciliate predation, food selectivity and impact on prey populations. Mar Ecol Prog Ser 130: 85-96
Atkinson A, Shreeve RS, Pakhomov EA, Priddle J, Blight SP, Ward P (1996) Zooplankton response to a phytoplankton bloom near South Georgia, Antarctica. Mar Ecol Prog Ser 144:195-210

Berggreen U, Hansen B, Kiørboe T (1988) Food size spectra, ingestion and growth of the copepod Acartia tonsa during development: implications for determination of copepod production. Mar Biol 99:341-352

Castellani C, Robinson C, Smith T, Lampitt RS (2005) Temperature affects respiration rate of Oithona similis. Mar Ecol Prog Ser 285:129-135

Dalpadado P, Ellertsen B, Melle W, Dommasnes A (2000) Food and feeding conditions of Norwegian springspawning herring (Clupea harengus) through its feeding migrations. ICES J Mar Sci 57:843-857

Fernández $F$ (1979) Particle selection in the nauplius of Calanus pacificus. J Plankton Res 4:313-328

Frost BW (1972) Effects of size and concentration of food particles on the feeding behavior of the marine planktonic copepod Calanus pacificus. Limnol Oceanogr 17:805-815

Fryer G (1986) Structure, function and behaviour, and the elucidation of evolution in copepods and other crustaceans. Syllogeus 58:150-157

Gaard E, Reinert J (2002) Pelagic cod and haddock juveniles on the Faroe plateau: distribution, diets and feeding habitats, 1994-1996. Sarsia 87:193-206

Gerritsen J, Strickler JR (1977) Encounter probabilities and community structure in zooplankton: a mathematical model. J Fish Res Board Can 34:73-82

Gifford DJ, Bohrer RN, Boyd CM (1981) Spines on diatoms: Do copepods care? Limnol Oceanogr 26:1057-1061

González HE, Smetacek V (1994) The possible role of the cyclopoid copepod Oithona in retarding vertical flux of zooplankton faecal material. Mar Ecol Prog Ser 113: $233-246$

Hopkins TL, Lancraft TM, Torres JJ, Donnelly J (1993) Community structure and trophic ecology of zooplankton in the Scotia Sea marginal ice zone in winter (1988). Deep-Sea Res 40:81-105

Irigoien X, Titelman J, Harris RP, Harbour D, Castellani C (2003) Feeding of Calanus finmarchicus nauplii in the Irminger Sea. Mar Ecol Prog Ser 262:193-200

Jakobsen HH (2001) Escape response of planktonic protists to fluid mechanical signals. Mar Ecol Prog Ser 214:67-78

Jiang H, Paffenhöfer GA (2004) Relation of behaviour of copepod juveniles to potential predation by omnivorous copepods: an empirical-modeling study. Mar Ecol Prog Ser 278: $225-239$

Kiørboe T, Saiz E (1995) Planktivorous feeding in calm and turbulent environments, with emphasis on copepods. Mar Ecol Prog Ser 122:135-145

Kiørboe T, Visser AW (1999) Predator and prey perception in copepods due to hydromechanical signals. Mar Ecol Prog Ser 179:81-95

Mullin MM, Brooks ER (1967) Laboratory culture, growth rate, and feeding behaviour of a planktonic marine copepod. Limnol Oceanogr 12:657-666

Paffenhöfer GA (1993) On the ecology of marine cyclopoid copepods (Crustacea, Copepoda). J Plankton Res 15: 37-55

Paffenhöfer GA (1998) On the relation of structure, perception and activity in marine planktonic copepods. J Mar Syst 15:457-473

Paffenhöfer GA, Lewis KD (1990) Perceptive performance and feeding behaviour of calanoid copepods. J Plankton Res 12:933-946

Paffenhöfer GA, Mazzocchi MG (2002) On some aspects of 
the behaviour of Oithona plumifera (Copepoda: Cyclopoida). J Plankton Res 24:129-135

Paffenhöfer GA, Strickler JR, Lewis KD, Richman S (1996) Motion behaviour of nauplii and early copepodid stages of marine planktonic copepods. J Plankton Res 18: 1699-1715

Rey C, Harris R, Irigoien X, Head R, Carlotti F (2001) Influence of algal diet on growth and ingestion of Calanus helgolandicus nauplii. Mar Ecol Prog Ser 216:151-165

Saiz E, Alcaraz M (1991) Effects of small-scale turbulence on development time and growth of Acartia grani (Copepoda: Calanoida). J Plankton Res 13:873-883

Saiz E, Kiørboe T (1995) Predatory and suspension feeding of the copepod Acartia tonsa in turbulent environments. Mar Ecol Prog Ser 122:147-158

Saiz E, Calbet A, Broglio E (2003) Effects of small-scale turbulence on copepods: the case of Oithona davisae. Limnol Oceanogr 48:1304-1311

Seuront L, Hwang JS, Tseng LC, Schmitt FG, Souissi S, Wong CK (2004) Individual variability in the swimming behaviour of the sub-tropical copepod Oncaea venusta (Copepoda: Poecilostomatoida). Mar Ecol Prog Ser 283:199-217

Strickler JR (1985) Feeding currents in calanoid copepods: two new hypotheses. Symp Soc Exp Biol 89:459-485

Svensen C, Kiørboe T (2000) Remote prey detection in Oithona similis: hydromechanical versus chemical cues. J Plankton Res 22:1155-1166

Takahashi K, Tiselius P (2005) Ontogenetic change of foraging behaviour during copepodite development of Acartia clausi. Mar Ecol Prog Ser 303:213-223

Tiselius P, Jonsson PR, Karrtvedt S, Olsen EM, Jordstad T

Editorial responsibility: Otto Kinne (Editor-in-Chief),

Oldendorf/Luhe, Germany
(1997) Effects of copepod foraging behaviour on predation risk: an experimental study of the predatory copepod Pareuchaeta norvegica feeding on Acartia clausi and A. tonsa (Copepoda). Limnol Oceanogr 42:164-170

Titelman J (2001) Swimming and escape behaviour of copepod nauplii: implications for predator-prey interactions among copepods. Mar Ecol Prog Ser 213:203-213

Titelman J, Kiørboe T (2003a) Motility of copepod nauplii and implications for food encounter. Mar Ecol Prog Ser 247: 123-135

Titelman J, Kiørboe T (2003b) Predator avoidance by nauplii. Mar Ecol Prog Ser 247:137-149

Turner JT, Levinsen H, Nielsen TG, Hansen BW (2001) Zooplankton feeding ecology: grazing on phytoplankton and predation on protozoans by copepod and barnacle nauplii in Disko Bay, West Greenland. Mar Ecol Prog Ser 221: 209-219

Uchima M, Hirano R (1986) Food of Oithona davisae (Copepoda: Cyclopoida) and the effect of food concentration at first feeding on the larval growth. Bull Plankton Soc Jpn $33: 21-28$

Uchima M, Hirano R (1988) Swimming behaviour of the marine copepod Oithona davisae: internal control and search for environment. Mar Biol 99:47-56

Van Duren LA, Videler JJ (1995) Swimming behaviour of developmental stages of the calanoid copepod Temora longicornis at different food concentrations. Mar Ecol Prog Ser 126:153-161

Van Duren LA, Stamhuis EJ, Videler JJ (2003) Copepod feeding currents: flow patterns, filtration rates and energetics. J Exp Biol 206:255-267

Submitted: April 10, 2006; Accepted: July 3, 2006

Proofs received from author(s): February 1, 2007 